\title{
A clinical audit of the diagnosis and management of chronic kidney disease in a primary care clinic
}

\author{
Jazlan Jamaluddin, Mohamed Syarif Mohamed Yassin, Siti Nuradliah Jamil, Mohd Azzahi \\ Mohamed Kamel, Mohamad Ya'akob Yusof
}

Jamaluddin J, Mohamed-Yassin MS, Jamil SN, et al. A clinical audit of the diagnosis and management of chronic kidney disease in a primary care clinic. Malays Fam Physician. 2021;16(3);68-76. https://doi.org/10.51866/oa1171

\section{Keywords:}

Chronic renal insufficiency,

clinical audit, diagnosis,

primary health care,

Malaysia

\section{Authors:}

\section{Mohamed Syarif Mohamed \\ Yassin \\ (Corresponding author) \\ MBBS(Monash), FRACGP(Australia) \\ Department of Primary Care \\ Medicine, Faculty of Medicine \\ Universiti Teknologi MARA, Selayang \\ Campus, Selangor, Malaysia \\ Email: syarif8258@uitm.edu.my}

\section{Jazlan Jamaluddin}

MD (Moscow)

Department of Primary Care

Medicine, Faculty of Medicine

Universiti Teknologi MARA, Selayang

Campus, Selangor, Malaysia

\section{Siti Nuradliah Jamil}

MBBS (UiTM)

Department of Primary Care

Medicine, Faculty of Medicine

Universiti Teknologi MARA, Selayang

Campus, Selangor, Malaysia

\section{Mohd Azzahi Mohamed Kamel}

MD (Crimea)

Department of Primary Care

Medicine, Faculty of Medicine

Universiti Teknologi MARA, Selayang

Campus, Selangor, Malaysia

\begin{abstract}
Introduction: This audit was performed to monitor the diagnosis and management of chronic kidney disease (CKD) according to the clinical practice guidelines (CPGs) of CKD 2018 in a primary care clinic.

Methods: Patients who attended the clinic from April to June 2019 and fulfilled the diagnosis of CKD were included in this study, except for those diagnosed with a urinary tract infection, pregnant women and those on dialysis. These criteria were set based on the CPGs. The standards were set following discussions with the clinic team members with reference to local guidelines, the 2017 United Kingdom National CKD audit and other relevant studies.

Results: A total of 384 medical records were included in this audit. Overall, 5 out of 20 criteria for processes and 3 of 8 clinical outcomes for CKD care did not meet the set standards. These included the following: documentation of CKD classification based on albumin category (43.8\%); CKD advice (19.0\%); dietitian referral (9.1\%); nephrologist referral (45.5\%); haemoglobin level monitoring (65.7\%); overall blood pressure (BP) control (45.3\%); BP readings for diabetic kidney disease (DKD) and non-DKD with $>1 \mathrm{~g} /$ day of proteinuria $(\leq 130 / 80 \mathrm{mmHg}, 37.0 \%)$; eGFR reduction of $<25 \%$ over the past year $(77.2 \%)$. Identified problems included the absence of a CKD registry, eGFR and albuminuria reports, and a dedicated team, among other factors.

Conclusions: Overall, 8 out of 28 criteria did not meet the standards of CKD care set for this audit. The problems identified in this audit have been addressed. Moreover, strategies have also been formulated to improve the diagnosis and management of CKD in this clinic.
\end{abstract}

\section{Introduction}

Chronic kidney disease (CKD) is a common but silent and under-recognised condition. It has become a global public health concern due to the increasing number of patients presenting with this disease, its risk of progression to end-stage renal disease (ESRD) and the high morbidity and mortality associated with it. ${ }^{1}$ CKD has been recognised as a strong risk factor for coronary events, which can result in increased mortality and a significant financial impact for patients and communities. ${ }^{2}$ In recent years, the incidence of CKD among developing countries has increased, which suggests that the economic status of a country could be linked to the development or recognition of ESRD or both. ${ }^{3}$ In 2010, 2.6 million individuals received renal replacement therapy (RRT) worldwide, with estimates of between 2.3 to 7.1 million individuals requiring RRT but not receiving it. ${ }^{4}$ It has been projected that the number of people on dialysis will more than double (to 5.4 million) by 2030, with the largest growth expected in Asia.

In Malaysia, an article based on the Malaysian National Health and Morbidity Survey 2011 reported that $9.1 \%$ of adults were found to have CKD; however, only $4 \%$ were aware of their diagnosis. ${ }^{5}$ Notably, CKD prevalence increased from $9.1 \%$ in 2011 to $15.5 \%$ in 2018. ${ }^{6}$ The 29th Annual Data Report of the United States Renal Data System, which included data from 74 countries, revealed that Malaysia had the highest average annual increase in the overall rates of ESRD incidence from 2003 to 2016. ${ }^{7}$ In 2016, among young adults aged 20 to 44 years worldwide, Malaysia ranked second behind the United States in ESRD incidence rate (111 patients per million of the general 
Mohamad Ya'akob Yusof MBBS (IIUM)

Department of Primary Care Medicine, Faculty of Medicine Universiti Teknologi MARA, Selayang Campus, Selangor, Malaysia population). If the current trend continues, it is projected that the number of patients with ESRD in Malaysia will reach 51000 in 2020 and 106000 in $2040 .^{8}$ This will cost the health care system an estimated RM1.5 billion and RM3.2 billion, respectively.

A local study conducted in primary care clinics demonstrated that the monitoring and management of CKD complications and their associated cardiovascular risk factors were poor.' Notably, the early detection and appropriate management of CKD have been shown to reduce the deterioration of kidney function by up to $50 \% .{ }^{10}$ Hence, primary healthcare services serve an important and challenging role in preventing CKD and providing the quality clinical management of CKD patients. Therefore, current CKD management practices must be assessed especially in community-based primary care clinics. A clinical audit is an approach that can be used to assess care. For this reason, a clinical audit was conducted among adult CKD patients attending a primary care clinic.

\section{Methods}

This audit was conducted from 1st July to 20th September 2019 in a primary care clinic on a university campus in Gombak District, Selangor, Malaysia. Patients who visited the clinic from 1st April to 30th June 2019 and fulfilled the diagnosis of CKD were included in the study.

\section{Clinic setting}

The primary care clinic is located in the large district of Gombak, which has a total population of 629971.11 The clinic has access to radiology, laboratory and referral services for other specialities. This clinic had an average of 80 patient attendances per day. All of the doctors working here are family medicine trainees and family medicine specialists. Patients normally see the same doctor for their appointments to ensure continuity of care. Patients who 'walk in' would be seen by any of the available doctors.

\section{Sampling and recruitment}

All patients aged 18 years and above who visited the clinic at least twice within the past year and had a renal profile or urine tests taken during the study period were screened for a diagnosis of CKD. In the CPGs, CKD is defined as either eGFR $<60 \mathrm{ml} / \mathrm{min} / 1.73 \mathrm{~m}^{2}$ and/or evidence of kidney damage that is present for more than 3 months. Markers of kidney damage include structural or functional abnormalities, decreased estimated glomerular filtration rate (eGFR), and albuminuria, which were screened from the electronic medical record (EMR) system by using the following keywords: chronic kidney disease, renal impairment, kidney transplant, polycystic kidney disease, hydronephrosis, benign prostatic hyperplasia, renal artery stenosis, renal tubular acidosis, diabetes insipidus, potassium wasting, magnesium wasting, Fanconi syndrome, proteinuria, cystinuria, glomerulonephritis, pyelonephritis, cortical scarring and small kidney. The exclusion criteria included patients diagnosed with a urinary tract infection, pregnant women and ESRD patients on dialysis.

Defining standards for CKD diagnosis and management

The criteria for this audit were defined according to the 2 nd edition of the Malaysian CPG on Management of CKD, which was published in 2018. ${ }^{12}$ The standard levels of performance for each of the criteria were set after discussions with the clinic team members based on the latest published standards of care, which include other local guidelines, the 2017 National CKD audit in the United Kingdom, a local audit by Iliza et al., and other relevant studies. ${ }^{9,13-24}$ The selected criteria represent the process and outcome measures of CKD management. Criteria for clinical care include the correct diagnosis of CKD with the documentation of classification based on the cause, glomerular filtration rate and albumin (CGA) category. Blood pressure (BP) measurement should also be performed at every visit. Other criteria for processes of care include obtaining a renal profile as well as urine albumin and glycosylated haemoglobin (HbA1c) levels at least once per year for patients with diabetic kidney disease (DKD). It was also agreed that the monitoring of CKD complications such as haemoglobin $(\mathrm{Hb})$, corrected calcium (cCa), phosphate (PO4) and alkaline phosphatase (ALP) levels should be performed at least once per year for patients with CKD stage G3 and higher.

Regarding CKD retardation measures, angiotensin-converting enzyme inhibitors (ACEIs) or angiotensin receptor blockers (ARBs) should be prescribed if indicated, unless contraindicated. Statin should also be started on patients unless contraindicated. Medications known to be associated with $\mathrm{CKD}$ such as non-steroidal anti-inflammatory drugs (NSAIDs) and long-term proton pump 
inhibitors (PPIs) should not be prescribed unless there is a clear indication. Patients with CKD should also be referred to a dietitian and CKD advice (avoidance or reduction of nephrotoxic agent exposure and CKDspecific dietary advice) should be provided and documented at least once in the past year. Patients who had indications for an ultrasound of the kidneys, ureter and bladder (KUB) (i.e., an eGFR reduction of $>5 \mathrm{ml} / \mathrm{min} / 1.73 \mathrm{~m}^{2}$ within 1 year or $10 \mathrm{ml} / \mathrm{min} / 1.73 \mathrm{~m}^{2}$ within 5 years, haematuria, symptoms or history of urinary tract obstruction, family history of polycystic kidney disease and age over 20 years, or when a renal biopsy is indicated) should have an ultrasound performed. Those who fulfilled the criteria for nephrology referral based on the CPGs (i.e., persistent heavy proteinuria [urine protein $\geq 1 \mathrm{~g} /$ day or urine protein: creatinine ratio (uPCR) $\geq 100 \mathrm{mg} /$ $\mathrm{mmol}$ ] despite optimal treatment, persistent isolated microscopic haematuria after excluding urogynaecological cause, persistent haematuria with proteinuria [urine protein $\geq 0.5 \mathrm{~g} /$ day or $\mathrm{uPCR} \geq 50 \mathrm{mg} / \mathrm{mmol}]$, rapidly declining renal function [eGFR loss of $>5 \mathrm{ml} / \mathrm{min} / 1.73 \mathrm{~m}^{2}$ in 1 year or $>10 \mathrm{ml} / \mathrm{min} / 1.73 \mathrm{~m}^{2}$ within 5 years], eGFR < $30 \mathrm{ml} / \mathrm{min} / 1.73 \mathrm{~m}^{2}$ [eGFR categories G4-G5], resistant hypertension [failure to achieve target blood pressure despite three antihypertensive agents, including a diuretic], suspected renal artery stenosis, suspected hereditary kidney disease, pregnant or when pregnancy is planned, persistent abnormalities of serum potassium, unexplained cause of CKD) should also be referred.

The clinical outcomes of CKD care were defined as good control if the latest documented values were BP $\leq 140 / 90 \mathrm{mmHg}$ for non-DKD with $<1 \mathrm{~g} /$ day of proteinuria; $\mathrm{BP} \leq 130 / 80 \mathrm{mmHg}$ for DKD or non-DKD with $>1 \mathrm{~g} /$ day of proteinuria; HbA1c $\leq 7 \%$ for $\mathrm{DKD} ; \mathrm{Hb} \geq 10.0 \mathrm{~g} / \mathrm{dL}$ with $\mathrm{cCa}$ and PO4 within the normal ranges for CKD stage G3 or higher. The eGFR reduction target was set at less than $25 \%$ over the past year.

Process of data collection and statistical analysis Demographic data and relevant clinical information were accessed via the EMR system. All relevant data were recorded electronically in an audit form that consisted of patients' socio-demographic profiles and past medical histories. This form also contained a checklist for measures of CKD care processes and the outcomes of CKD care. Data were analysed using the Statistical
Package for Social Science (SPSS) version 25. A Shapiro-Wilk test was performed to check the distribution of the data. Means with standard deviations (SDs) were used to describe normally distributed data, while median with interquartile ranges (IQRs) were used for non-normally distributed data. Frequencies and percentages were used to describe categorical data.

\section{Results}

A total of 897 patients attended the clinic during the study period and met the screening criteria. These patients were then reviewed for a diagnosis of CKD and the exclusion criteria. Overall, 513 patients were excluded since they did not receive a diagnosis of CKD or met the exclusion criteria. Thus, a total of 384 patients were included in the present study. Figure 1 presents a flow diagram of this study.

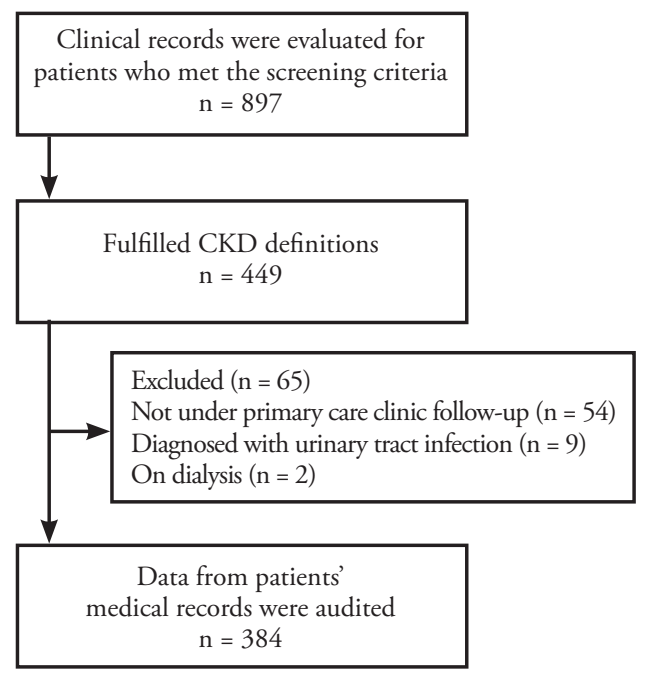

Figure 1. Flow diagram of the audit.

The mean age of the patients was $65.4 \pm$ 9.3 years. Most of the patients were males (70.6\%) and Malay (82.3\%). The mean body mass index (BMI) was $28.5 \pm 5.4 \mathrm{~kg} / \mathrm{m}^{2}$. Most of the patients were in CKD stage G3 and albuminuria category A1. More than half of the patients had concurrent hypertension and diabetes mellitus. The demographic and clinical characteristics of the audited patients are presented in Table 1 .

Overall, 5 out of 20 criteria for CKD care processes did not meet the standards set for this audit. These include the documentation of CKD classification based on albumin category ( $43.8 \%$ versus the standard of $65 \%$ ), haemoglobin level monitoring (65.7\%), providing and documenting CKD advice $(19.0 \%)$ and referral to dietitians (9.1\%). 
Moreover, referral to a nephrologist for patients meeting the referral criteria did not meet the set standard (45.5\%). The measures of processes for CKD care are outlined in Table 2.

Overall, three out of eight criteria for the clinical outcomes of CKD care did not meet the set standards. These included overall BP control, $\mathrm{BP} \leq 130 / 80 \mathrm{mmHg}$ for $\mathrm{DKD}$ or non-DKD with $>1 \mathrm{~g} /$ day of proteinuria, and eGFR reduction of $<25 \%$ over the past year. The clinical outcomes of CKD care are presented in Table 3.

Problems identified in this audit included the absence of a CKD registry, eGFR and albuminuria reports, and a dedicated noncommunicable team. Improvements could also be made to the EMR system, such as the creation of a compulsory section for diagnosis, automatic reminders, manual or electronic checklists, and order sets.

Table 1. Socio-demographic and clinical characteristics of respondents $(\mathrm{N}=384)$.

\begin{tabular}{|c|c|c|c|c|c|c|c|}
\hline $\begin{array}{l}\text { Socio-demographic and } \\
\text { clinical characteristics }\end{array}$ & $\begin{array}{l}\text { General } \\
\mathrm{n}=384\end{array}$ & $\begin{array}{l}\text { Stage G1 } \\
\mathbf{n}=23\end{array}$ & $\begin{array}{l}\text { Stage G2 } \\
\mathbf{n}=75\end{array}$ & $\begin{array}{l}\text { Stage G3a } \\
\mathrm{n}=138\end{array}$ & $\begin{array}{l}\text { Stage G3b } \\
\mathrm{n}=106\end{array}$ & $\begin{array}{l}\text { Stage G4 } \\
\mathrm{n}=38\end{array}$ & $\begin{array}{l}\text { Stage } \mathrm{G} 5 \\
\mathrm{n}=4\end{array}$ \\
\hline Age (years), mean $\pm S D$ & $65.4 \pm 9.3$ & $58.4 \pm 7.5$ & $62.6 \pm 10.2$ & $65.7 \pm 7.7$ & $66.5 \pm 9.9$ & $71.1 \pm 8.0$ & $67.20 \pm 98$ \\
\hline $\begin{array}{l}\text { Gender, n (\%) } \\
\text { Male } \\
\text { Female }\end{array}$ & $\begin{array}{l}271(70.6) \\
113(29.4)\end{array}$ & $\begin{array}{l}10(43.5) \\
13(56.5)\end{array}$ & $\begin{array}{l}53(70.7) \\
22(29.3)\end{array}$ & $\begin{array}{l}109(79.0) \\
29(21.0)\end{array}$ & $\begin{array}{l}71(67.0) \\
35(33.0)\end{array}$ & $\begin{array}{l}25(65.8) \\
13(34.2)\end{array}$ & $\begin{array}{l}3(75.0) \\
1(25.0)\end{array}$ \\
\hline $\begin{array}{l}\text { Ethnicity, n (\%) } \\
\text { Malay } \\
\text { Chinese } \\
\text { Indian } \\
\text { Others }\end{array}$ & $\begin{array}{c}316(82.3) \\
54(14.1) \\
11(2.9) \\
3(0.8)\end{array}$ & $\begin{array}{c}14(60.9) \\
7(30.4) \\
2(8.7) \\
0(0)\end{array}$ & $\begin{array}{c}67(89.3) \\
7(9.3) \\
1(1.3) \\
0(0)\end{array}$ & $\begin{array}{c}116(84.1) \\
18(13.0) \\
2(1.4) \\
2(1.4)\end{array}$ & $\begin{array}{c}85(80.2) \\
17(16.0) \\
3(2.8) \\
1(0.9)\end{array}$ & $\begin{array}{c}32(84.2) \\
3(7.9) \\
3(7.9) \\
0(0)\end{array}$ & $\begin{array}{c}2(50.0) \\
2(50.0) \\
0(0) \\
0(0)\end{array}$ \\
\hline $\mathrm{BMI}$, mean $\pm \mathrm{SD}$ & $28.5 \pm 5.4$ & $28.4 \pm 5.1$ & $29.0 \pm 6.1$ & $28.2 \pm 5.3$ & $28.6 \pm 4.7$ & $27.4 \pm 6.1$ & $31.8 \pm 5.1$ \\
\hline eGFR, median $\pm \mathrm{IQR}$ & $50.8 \pm 22.2$ & $96.0 \pm 8.0$ & $73.0 \pm 15.6$ & $52.6 \pm 7.2$ & $38.5 \pm 7.1$ & $24.1 \pm 5.96$ & $12.2 \pm 5.6$ \\
\hline $\begin{array}{l}\text { Albuminuria category, n (\%) } \\
\text { A1 } \\
\text { A2 } \\
\text { A3 } \\
\text { Unknown }\end{array}$ & $\begin{array}{c}161(41.9) \\
110(28.6) \\
93(24.2) \\
20(5.2)\end{array}$ & $\begin{array}{c}8(34.8) \\
13(56.5) \\
2(8.7) \\
0(0)\end{array}$ & $\begin{array}{c}26(34.7) \\
30(40.0) \\
18(24.0) \\
1(1.3)\end{array}$ & $\begin{array}{c}76(55.1) \\
31(22.5) \\
24(17.4) \\
7(5.1)\end{array}$ & $\begin{array}{c}13(34.2) \\
8(21.1) \\
15(39.5) \\
10(9.4)\end{array}$ & $\begin{array}{c}13(34.2) \\
8(21.1) \\
15(39.5) \\
2(5.3)\end{array}$ & $\begin{array}{c}0(0) \\
0(0) \\
4(100) \\
0(0)\end{array}$ \\
\hline Diabetes mellitus only, $\mathbf{n}(\%)$ & $94(24.5)$ & $7(30.4)$ & $17(22.7)$ & $38(27.5)$ & $22(20.7)$ & $8(21.1)$ & $2(50)$ \\
\hline Hypertension only, n (\%) & $25(6.5)$ & $2(8.7)$ & $4(5.3)$ & $9(6.5)$ & $8(7.5)$ & $2(5.3)$ & $0(0)$ \\
\hline $\begin{array}{l}\text { Diabetes mellitus and } \\
\text { hypertension, } \mathbf{n}(\%)\end{array}$ & $221(57.6)$ & $6(26.1)$ & $36(48.0)$ & $79(57.2)$ & $70(66.0)$ & $28(73.7)$ & $2(50)$ \\
\hline
\end{tabular}

Table 2. Measures of processes for CKD care.

\begin{tabular}{l|c|c|c|c}
\hline Criteria & Frequency & $\begin{array}{c}\text { Result } \\
(\%)\end{array}$ & $\begin{array}{c}\text { Standard } \\
(\%)\end{array}$ & Achievement \\
\hline $\begin{array}{l}\text { All patients who fulfilled CKD definitions were } \\
\text { correctly diagnosed with CKD. }\end{array}$ & $320 / 384$ & 83.3 & 70 & Achieved \\
\hline $\begin{array}{l}\text { Classification of CKD based on cause is } \\
\text { documented. }\end{array}$ & $334 / 384$ & 87.0 & 50 & Achieved \\
\hline $\begin{array}{l}\text { Classification of CKD based on GFR category is } \\
\text { documented. }\end{array}$ & $296 / 384$ & 77.1 & 65 & Achieved \\
\hline $\begin{array}{l}\text { Classification of CKD based on albumin category } \\
\text { is documented. }\end{array}$ & $168 / 384$ & 43.8 & 65 & Not Achieved \\
\hline \begin{tabular}{l} 
Blood pressure was recorded at all follow-up visits. \\
\hline $\begin{array}{l}\text { A renal profile was performed at least once in the } \\
\text { past year. }\end{array}$
\end{tabular} & $384 / 384$ & 100 & 95 & Achieved \\
\hline $\begin{array}{l}\text { A urine protein analysis was performed at least } \\
\text { once in the past year. }\end{array}$ & $362 / 384$ & 94.3 & 90 & Achieved \\
\hline $\begin{array}{l}\text { HbAlc was assessed at least once in the past year } \\
\text { for DKD.* }\end{array}$ & $264 / 268$ & 98.5 & 50 & Achieved \\
\hline $\begin{array}{l}\text { Hb was assessed at least once in the past year for } \\
\text { patients with CKD stage G3 or higher.* }\end{array}$ & $188 / 286$ & 65.7 & 75 & Not Achieved \\
\hline $\begin{array}{l}\text { Calcium was assessed at least once in the past year } \\
\text { for patients with CKD stage G3 or higher.* }\end{array}$ & $24 / 286$ & 8.4 & 5 & Achieved \\
\hline $\begin{array}{l}\text { Phosphate was assessed at least once in the past } \\
\text { year for patients with CKD stage G3 or higher.* }\end{array}$ & $23 / 286$ & 8.0 & 5 & Achieved \\
\hline
\end{tabular}




\begin{tabular}{l|c|c|c|c}
\hline Criteria & Frequency & $\begin{array}{c}\text { Result } \\
(\%)\end{array}$ & $\begin{array}{c}\text { Standard } \\
(\%)\end{array}$ & Achievement \\
\hline $\begin{array}{l}\text { ALP was assessed at least once in the past year for } \\
\text { patients with CKD stage G3 or higher. }\end{array}$ & $248 / 286$ & 86.7 & 5 & Achieved \\
\hline $\begin{array}{l}\text { ACEI or ARB was prescribed if indicated unless } \\
\text { contraindicated.* }\end{array}$ & $280 / 344$ & 81.4 & 75 & Achieved \\
\hline Statin was prescribed unless contraindicated.* & $353 / 383$ & 92.2 & 70 & Achieved \\
\hline No NSAIDs were prescribed in the past year. & $343 / 384$ & 89.3 & 75 & Achieved \\
\hline $\begin{array}{l}\text { No long-term PPIs were prescribed unless there } \\
\text { was a clear indication.* }\end{array}$ & $310 / 338$ & 91.7 & 80 & Achieved \\
\hline $\begin{array}{l}\text { CKD advice was given and documented at least } \\
\text { once in the past year. }\end{array}$ & $73 / 384$ & 19.0 & 65 & Not Achieved \\
\hline $\begin{array}{l}\text { Patient with CKD was referred to a dietitian. } \\
\text { KUB ultrasound was performed for the patient, } \\
\text { with abnormalities suggestive of a CKD requiring } \\
\text { ultrasound.* }\end{array}$ & $159 / 249$ & 63.9 & 25 & Achieved \\
\hline $\begin{array}{l}\text { Patient with CKD who fulfils referral criteria was } \\
\text { referred to a nephrologist. }\end{array}$ & $76 / 167$ & 45.5 & 70 & Not Achieved \\
\hline CKD Chroned
\end{tabular}

CKD - Chronic kidney disease, GFR - glomerular filtration rate, DKD - diabetic kidney disease, ALP - alkaline phosphatase, ACEI - angiotensin-converting enzyme inhibitor, ARB - angiotensin receptor blockers, NSAIDs - non-steroidal anti-inflammatory drugs, PPIs - proton pump inhibitors, KUB - kidneys, ureter and bladder.

${ }^{*} \mathrm{n}$ is not equal to 384 .

Table 3. Clinical outcomes of CKD care.

\begin{tabular}{|c|c|c|c|c|c|}
\hline Variables & Mean \pm SD & Frequency & $\begin{array}{l}\text { Result } \\
(\%)\end{array}$ & $\begin{array}{c}\text { Standard } \\
(\%)\end{array}$ & Achievement \\
\hline $\begin{array}{l}\mathrm{BP} \\
\mathrm{BP} \leq 140 / 90 \mathrm{mmHg}^{\mathrm{a} *} \\
\mathrm{BP} \leq 130 / 80 \mathrm{mmHg}^{\mathrm{b} *} \\
\text { Total achieved target }\end{array}$ & & $\begin{array}{l}72 / 108 \\
102 / 276 \\
174 / 384\end{array}$ & $\begin{array}{l}66.7 \\
37.0 \\
45.3\end{array}$ & $\begin{array}{l}50 \\
50 \\
50\end{array}$ & $\begin{array}{c}\text { Achieved } \\
\text { Not Achieved } \\
\text { Not Achieved }\end{array}$ \\
\hline $\begin{array}{l}\text { HbAlc* } \\
\text { Mean } \pm \text { SD, } \% \\
\text { HbAlc } \leq 7 \%\end{array}$ & $7.6 \pm 1.6$ & $119 / 264$ & 45.1 & 30 & Achieved \\
\hline $\begin{array}{l}\text { Haemoglobin* } \\
\text { Mean } \pm \mathrm{SD}, \mathrm{g} / \mathrm{dL} \\
\geq 10.0\end{array}$ & $12.9 \pm 1.8$ & $181 / 188$ & 96.3 & 70 & Achieved \\
\hline $\begin{array}{l}\text { Corrected calcium* } \\
\text { Mean } \pm \text { SD, mmol/L } \\
\text { Normal }(2.20-2.55)\end{array}$ & $2.32 \pm 0.13$ & $22 / 24$ & 91.7 & 50 & Achieved \\
\hline $\begin{array}{l}\text { Phosphate* } \\
\text { Mean } \pm \text { SD, mmol/L } \\
\text { Normal }(0.81-1.45)\end{array}$ & $1.29 \pm 0.20$ & $19 / 23$ & 82.6 & 20 & Achieved \\
\hline Reduction of eGFR $<25 \%$ in 1 year* & & $288 / 373$ & 77.2 & 90 & Not Achieved \\
\hline
\end{tabular}

a For non-DKD with $<1 \mathrm{~g} /$ day of proteinuria.

b For DKD or non-DKD with $>1 \mathrm{~g} /$ day of proteinuria.

${ }^{*} \mathrm{n}$ is not equal to 384 .

\section{Discussion}

This audit found that most of the processes and outcomes of care in the clinic were comparable to the aforementioned local and international standards of care. However, a few criteria did not meet the set standards. Among the processes of CKD care, the classification of CKD based on albumin category was not routinely documented. Our audit found that although test results were often reviewed, the documentation of CKD classification based on CGA and its monitoring were often missing. Notably, the renal profile and urine test reports in this institution do not include protein classification. Hence, doctors must manually classify albuminuria, which is time-consuming. This could explain why the documentation of this important clinical information often did not occur. 
Haemoglobin levels were also not regularly monitored. Although the standards were met, calcium and phosphate levels were also not regularly assessed. These findings are consistent with results from the UK National CKD audit, which showed that monitoring for CKD complications was also not routinely performed. ${ }^{13}$ Moreover, most of these investigations (e.g., haemoglobin and ALP levels) were performed for other reasons, such as to investigate for prolonged fever or as part of default liver function tests. The monitoring of complications was more commonly performed in patients co-managed with a nephrologist. Therefore, appropriate and earlier referral to a nephrologist is important since it has been shown to reduce mortality and hospital stay, thereby achieving higher haemoglobin levels and improved dialysis preparation. ${ }^{25}$ However, less than half of the patients who warranted a nephrology referral were referred. One reason for this could be that the doctors were unaware of the deterioration in eGFR since it is not included as part of the renal profile report in this clinic. Since eGFR must be manually calculated, it could easily be skipped in a busy setting such as this. Moreover, this clinic does not have a dedicated non-communicable disease (NCD) team and respective registry that can help to identify and track the recommended monitoring of CKD patients. There is also a lack of automatic reminders in the EMR system and manual or electronic checklists available in the clinic to help remind doctors of necessary investigations and monitoring for CKD patients.

CKD advice and dietitian referrals were also not sufficiently documented in the medical records of audited patients. However, it is possible that CKD advice had been given to these patients but not documented in their medical records. Alternatively, such information could have been documented in the previous EMR system, which is no longer used in this clinic.

Despite ACEIs or ARBs being prescribed to more than $80 \%$ of patients, an inadequate number of patients achieved their target BP, especially for those with DKD or non-DKD with $>1 \mathrm{~g} /$ day of proteinuria. This finding is similar to a recent local study in which $41.9 \%$ of patients achieved their target BP. Possible reasons for not achieving the target BP may include medication non-adherence, polypharmacy, multiple co-morbidities and disease complications. Since this audit included elderly patients, individualised and more lenient targets might be used by the primary care doctors, as recommended by local hypertension guidelines.

There were also more patients who had an eGFR reduction of $>25 \%$ in 1 year than the standards set for this audit. As previously discussed, the doctors may not be aware of this deterioration since this clinic does not include eGFR results and albuminuria classification. Therefore, CKD retardation measures may not be adequately performed. It is also possible that doctors in this clinic may adopt a less aggressive approach to managing most of the elderly patients included in this audit due to the potentially harmful side effects that may occur.

On the positive side, this audit has also found several commendable achievements of this clinic in terms of CKD care. Regarding the care process, BP was measured and recorded in all patients at every visit over the past year. This achievement could be explained by the fact that all patients were required to go through a pre-assessment room, where blood pressure, heart rate, weight, height and waist circumference were measured. These measurements were performed before a patient could see a doctor. The clinic had managed to monitor the renal profile, urine protein and HbAlc of more than $90 \%$ of the audited patients, which exceeded the set standards. These results are similar to those of a previous audit in the UK. ${ }^{15}$ This may be due to the ease of access to in-house laboratory services, which ensured the timely return of test results. The percentage of patients attaining proposed glycaemic control was also found to be in line with the standard set. Among the 264 (98.5\%) patients with DKD who had an $\mathrm{HbA1c}$ test performed in the past year, the mean HbA1c level was $7.6 \pm 1.6 \%$, with 119 (45.1\%) having good glycaemic control. Notably, these results are slightly better than those of another local study. ${ }^{9}$ The audits, which were also conducted at primary care facilities, found that less than $40 \%$ of patients had HbA1c levels of $\leq 7.0 \%$. The better results achieved in this audit could be due to the availability of more costly oral hypoglycaemic agents (e.g., SGLT2 inhibitors and gliptins) and analogue insulin (e.g., aspart, glargine, and detemir). Furthermore, the patients in this audit may be better educated to manage their condition since the clinic utilises a self-management booklet to assist with their management. ${ }^{26}$ 
Several recommendations were made during the presentation of the audit findings. Firstly, the clinic has been advised to establish a registry for CKD and NCD patients. Clinical registries have been shown to improve processes of care, healthcare utilisation and clinical outcomes. ${ }^{27}$ This will also facilitate a thorough evaluation of individual patient care, including timely reminders for important monitoring tests (e.g., annual eGFR and urine protein) and the assessment of CKD complications. Likewise, it is also important to develop an efficient clinical information system to establish a comprehensive registry for patients in this clinic. This may be achieved by introducing a required section for diagnosis based on the International Classification of Diseases (ICD)-10 for each medical record entry, which will make identifying patients with CKD easier. The layout of the clinical information system should also be simplified, especially to improve ease of access for pathology orders. Order sets are a type of clinical decision support system where a limited set of evidence-based tests exists for a series of indications. Notably, the incorporation of order sets into a computerised physician order entry system was shown to be effective in reducing the number of laboratory tests ordered, whilst also improving adherence to guidelines and achieving better treatment outcomes. ${ }^{28}$ This will be very helpful in the management of the patients in this clinic.

Next, the establishment of a dedicated NCD team in the clinic has also been proposed. An NCD team comprising multidisciplinary practitioners including medical specialists, pharmacists, dietitians, nurses and medical assistants has been shown to improve care, lower all-cause mortality, decrease hospitalisation rates and slow eGFR decline in patients with CKD. ${ }^{29}$ A prepared, proactive and trained multidisciplinary care team with clearly defined roles and responsibilities should be introduced along with regular updates on evidence-based care through ongoing medical education. In the management of chronic diseases, informed and active patients will improve their health outcomes. ${ }^{26}$ Therefore, a dedicated NCD team may help with patients' empowerment in managing their health. Supplementary toolkits such as patient information leaflets or booklets, calendar flipcharts and quick reference guides can also be used to aid decision making during consultations. A quick reference guide that includes the target, monitoring requirements, nephrology referral and ultrasound indications based on local CKD CPGs and the clinical action plan for CKD by Kidney Health Australia was also developed by the audit team for the clinic and made available in every consultation room. ${ }^{30}$

Finally, a further discussion with the pathology department was suggested with regards to the addition of calculated eGFR and albuminuria classification in their pathology reports. International guidelines have continuously recommended the reporting of calculated eGFR and the use of the Kidney Disease Improving Global Outcomes (KDIGO) 2012 classification of albuminuria in laboratory reports. The 2009 Chronic Kidney Disease-Epidemiology Collaboration (CKD-EPI) creatinine equation is currently recommended since it has shown superiority over the Modification of Diet in Renal Disease (MDRD) equation in Western and Malaysian populations. ${ }^{12}$ However, routine eGFR levels are currently absent in most pathology reports in Malaysia. It is hoped that the adoption of these recommendations will further improve CKD care in the clinic. A future audit will be able to gauge the success of changes implemented in the clinic.

\section{Limitations}

This audit was limited by the lack of a CKD registry in the clinic, which may have resulted in an inaccurate number of CKD patients being audited. Retrospectively auditing EMRs might not reflect the clinician-patient consultations where advice was given but not documented. There was also a change of the clinic's EMR system in 2016, which resulted in difficulties retrieving previously recorded information (e.g., dietitian referrals).

\section{Conclusion}

In summary, 5 out of 20 criteria for CKD care processes and 3 out of 8 criteria for the clinical outcomes of CKD care did not meet the standards set for this audit. The problems identified in this audit have been addressed and strategies have been implemented to improve the diagnosis and management of CKD in this clinic. Another audit will be performed in the future to assess the outcomes of any implemented improvements. 


\section{Acknowledgements}

The authors would like to acknowledge the IT department of the Faculty of Medicine, Universiti Teknologi MARA (UiTM) for providing the initial patient list for this audit. We would also like to extend our gratitude to all of the UiTM Primary Care Clinic staff who aided us in this study.

\section{Competing interests}

None declared.

\section{Ethical approval}

This study was approved by the Universiti Teknologi MARA Research Ethics Committee (REC/677/19).

\section{Funding}

None

\section{How does this paper make a difference to general practice?}

- Increases awareness and highlights the importance of the diagnosis and appropriate management of chronic kidney disease (CKD) in primary care settings in Malaysia.

- May serve as baseline targets for future audits on CKD.

- The recommendations from this audit may be considered in other primary care clinics to improve CKD management.

\section{References}

1. Wang H, Naghavi M, Allen C, et al. Global, regional, and national life expectancy, all-cause mortality, and cause-specific mortality for 249 causes of death, 1980-2015: A systematic analysis for the Global Burden of Disease Study 2015. Lancet. 2016;388(10053):1459-544.

2. Tonelli M, Muntner P, Lloyd A, et al. Risk of coronary events in people with chronic kidney disease compared with those with diabetes: a population-level cohort study. Lancet. 2012 Sep;380(9844):807-14.

3. Wetmore JB, Collins AJ. Global challenges posed by the growth of end-stage renal disease. Ren Replace Ther. 2016 Dec 23;2(1):15.

4. Liyanage $\mathrm{T}$, Ninomiya $\mathrm{T}$, Jha $\mathrm{V}$, et al. Worldwide access to treatment for end-stage kidney disease: A systematic review. Lancet. 2015;385(9981):1975-82.

5. Hooi LS, Ong LM, Ahmad G, et al. A population-based study measuring the prevalence of chronic kidney disease among adults in West Malaysia. Kidney Int. 2013;84(5):1034-40.

6. Saminathan TA, Hooi LS, Mohd Yusoff MF, et al. Prevalence of chronic kidney disease and its associated factors in Malaysia; findings from a nationwide population-based crosssectional study. BMC Nephrol. 2020 Dec 14;21(1):344.
7. United States Renal Data System. 2018 USRDS Annual data report: Executive summary. Am J Kidney Dis. 2019;73(1):A9A22.

8. Bujang MA, Adnan TH, Hashim NH, et al. Forecasting the incidence and prevalence of patients with end-stage renal disease in Malaysia up to the year 2040. Int J Nephrol. 2017;2017:1-5.

9. Idris I, Tohid H, Muhammad NA, et al. Anaemia among primary care patients with type 2 diabetes mellitus (T2DM) and chronic kidney disease (CKD): A multicentred crosssectional study. BMJ Open. 2018;8(12):1-9.

10. Weckmann GFC, Stracke S, Haase A, et al. Diagnosis and management of non-dialysis chronic kidney disease in ambulatory care: a systematic review of clinical practice guidelines. BMC Nephrol. 2018 Dec 11;19(1):258.

11. Department of Statistics Malaysia. Population Distribution and Basic Demographic Characteristics 2010 [Internet]. Putrajaya: Department of Statistics, Malaysia; 2013. Available from: https://www.mycensus. gov.my/banci/www/admin/uploads/ penerbitanpdf/13.pdf.
12. Ministry of Health Malaysia. Clinical Practice Guidelines: Management of Chronic Kidney Disease. 2nd ed. [Internet]. Malaysian Health Technology Assessment Section (MaHTAS); 2018. Available from: http://www.acadmed. org. my/view_file.cfm?fileid=898.

13. Nitsch D, Caplin B, Hull S, et al. First National CKD Audit Report 2017 [Internet]. London; 2017. Available from: https://www. lshtm.ac.uk/files/ckd_audit_report.pdf.

14. Cole NI, Liyanage H, Suckling RJ, et al. An ontological approach to identifying cases of chronic kidney disease from routine primary care data: A cross-sectional study. BMC Nephrol. 2018;19(1):4-9.

15. Milne N. Improving the quality of diabetes care: An audit tool for chronic kidney disease. Diabetes Prim Care. 2014;16(2):78-83.

Available from: https://www.diabetesonthenet com/resources/details/improving-the-qualityof-diabetes-care-an-audit-tool-for-chronickidney-disease.

16. Chew BH, Palikat JM, Nur Syamimi A, et al. An audit of type 2 diabetes care in a Malaysian public community Polyclinic. Pertanika J Sci Technol. 2012;20(1):97-102. 
17. Patel HR, Pruchnicki MC, Hall LE. Assessment for chronic kidney disease service in high-risk patients at community health clinics. Ann Pharmacother. 2005;39(1):22-7.

18. Mousavi M, Dashti-Khavidaki S, Khalili H, et al. Impact of clinical pharmacy services on stress ulcer prophylaxis prescribing and related cost in patients with renal insufficiency. Int J Pharm Pract. 2013;21(4):263-9.

19. McIntyre NJ, Fluck R, McIntyre C, et al. Treatment needs and diagnosis awareness in primary care patients with chronic kidney disease. Br J Gen Pract. 2012;62(597):227-32.

20. Tan F, Chan G, Wong JS, et al. Standard of care for type 2 diabetic patients in a public hospital general medical clinic: Report of a self-audit. Med J Malaysia. 2008;63(3):224-8.

21. Goodall P, Rajapakse A. Audit on early detection and primary prevention of chronic kidney disease in patients admitted to the healthcare of the elderly wards in a district general hospital in UK. Int J Prev Med. 2013;4(4):493-5.

22. Sprangers B, Evenepoel P, Vanrenterghem Y. Late referral of patients with chronic kidney disease: No time to waste. Mayo Clin Proc. 2006;81(11):1487-94.
23. Wong H, Goh B. Twenty Forth Report of the Malaysian Dialysis and Transplant 2016 [Internet]. 24th ed. (Wong H, Goh B, editors.) Kuala Lumpur: The National Renal Registry; 2018. Available from: https:// www.msn.org.my/msn/Doc/PublicDoc_PB/ Publication/mdtr2016/All Chapters.pdf.

24. Halbesma N, Kuiken D-S, Brantsma AH, et al. Macroalbuminuria Is a better risk marker than low estimated GFR to identify individuals at risk for accelerated GFR loss in population screening. J Am Soc Nephrol. 2006 Sep;17(9):2582-90.

25. Smart NA, Titus TT. Outcomes of Early versus Late Nephrology Referral in Chronic Kidney Disease: A Systematic Review. Am J Med. 2011 Nov;124(11):1073-1080.e2.

26. Ramli AS, Selvarajah S, Daud MH, et al. Effectiveness of the EMPOWER-PAR intervention in improving clinical outcomes of type 2 diabetes mellitus in primary care: A pragmatic cluster randomised controlled trial. BMC Fam Pract. 2016 Dec 14;17(1):157.

27. Hoque DME, Kumari V, Hoque M, et al. Impact of clinical registries on quality of patient care and clinical outcomes: A systematic review. PLoS One. 2017 Sep 8;12(9):e0183667.
28. Chan AJ, Chan J, Cafazzo JA, et al. Order sets in health care: A systematic review of their effects. Int J Technol Assess Health Care. 2012 Jul 14;28(3):235-40.

29. Shi Y, Xiong J, Chen Y, et al. The effectiveness of multidisciplinary care models for patients with chronic kidney disease: A systematic review and meta-analysis. Int Urol Nephrol. 2018 Feb;50(2):301-12.

30. Stevens P, O’Donoghue D, De Lusignan S. Chronic Kidney Disease (CKD) Management in General Practice [Internet]. 4th ed. Kidney Health Australia; 2020. Available from: https://kidney.org.au/uploads/resources/ CKD-Management-in-Primary-Care_ handbook_2020.1.pdf. 